\title{
Bibliometric analysis about compassion fatigue based on Web of Science database
}

Original article

Xi-Liang Kang, Xiao Gao*

Operating Room of Affiliated Hospital of Taishan Medical University, Taian, Shandong 271000, China

Received: 6 August 2018; Accepted: 19 October 2018; Published: 20 June 2019

Abstract: Objective: To analyze the related foreign literature about compassion fatigue (CF) and to provide the basis for further improving the level of research in this field.

Methods: Based on the Web of Science core database and its own analysis function, HistCite analysis software was used to study the diploma research about CF.

Results: A total of 652 paper were retrieved, the output of literature showed an increasing trend year by year. The United States ranked first, and China ranked eleventh. The "Oncology Nursing Forum" had the largest number of articles (4.0\%). The main research direction was in nursing (29.6\%), and the main research output was from articles $(73.2 \%)$. The key words highly cited were "compassion" and "fatigue". Figley was the author of the high-yield field, and mainly research institutions were universities. The highly cited article was entitled "Compassion fatigue: Psychotherapists' chronic lack of self-care".

Conclusions: In recent years, the related heat of CF has been high fever. Our research in this field is still in the primary stage, and it needs to be further excavated and promoted.

Keywords: compassion • fatigue $\bullet$ Web of Science • literature measurement

(c) Shanxi Medical Periodical Press.

\section{Introduction}

For a long time, people have focused their attention on injured people, and there are few intervention studies on the psychological crisis of the people (such as medical staff, firefighters, and counselors). However, the compassion of the helping person is directly related to the mental health of the recipient. In 1995, Figley ${ }^{1}$ formally proposed the word "compassion fatigue" (CF) and introduced it to the psychological health of the people. $\mathrm{CF}^{2}$ refers to the compassion of rescuers in the process of rescue, which is mainly manifested by the reduction of compassion, posttraumatic stress disorder symptoms, and burnout. It is an indirect psychological trauma. However, with the mass renewal of CF literature at home and abroad, it is very important to carry out scientific and efficient analysis and management of the literature. Based on the core data of Web of Science (WOS), we use HistCite bibliometric software to objectively analyze the literature related to empathy fatigue,

How to cite this article: Kang X-L, Gao X. Bibliometric analysis about compassion fatigue based on Web of Science database. Front Nurs. 2019; 2: xx-xx. 
aiming to explore the hot trend in this field, and provide a basis for related scientific research.

\section{Subjects and methods}

\subsection{Sources and retrieval strategies}

In this study, the largest and most recognized global influence academic authoritative foreign language database WOS was used as the main retrieval tool. Topic selection field filled with "TS=(Compassion Fatigue)" in the search strategy, with no restriction on time, language, and literature type. A total of 652 articles were retrieved; data download date was November 23, 2017. When retrieved the information, selected the "full record and reference" and saved as "pure text" to the specified path.

\subsection{Tools and methods}

This study was based on the WOS self-analysis function and used HistCite, which is an application of Dr. Garfield in 2001. ${ }^{3}$ The software not only can quickly locate the important documents, a field of authors, journals, and research institutions, but also can generate a complete set of citation historiography visualization map, know the latest research and development of accurate knowledge of the field, develop comprehensive analysis and mining of information retrieval data, explore the development trend in the field of empathy and fatigue research focus.

\section{Result}

\subsection{Trend and state distribution of CF}

There were a total of 652 literatures, and the study found that since 1990, the global literature on CF growth year after year, especially from 2011 to this year, was almost linear field of growth. Since 2011, the field accounted for $76.1 \%$ of the total issued documents. See Figure 1.

For the country and region, the total volume of the United States was 335 , accounting for $51.4 \%$ of the total literature. Australia and Canada ranked the second place. The number of papers in mainland China ranked eleventh; the total number was nine, accounting for $1.4 \%$ of the total number of documents. See Table 1 for details.

\subsection{Journal of articles}

This study analyzed the periodicals of relevant sources. It was found that the since the establishment of the database, the journal that published the most relevant literature of CF was "Oncology Nursing Forum (Oncology Nursing Forum)", with a total of 26 published papers and $4 \%$ of documents $4 \%$; the second journal was "Clinical Journal of Oncology Nursing (Journal of Clinical Cancer Care)", which published 19 articles. In addition, from the impact of the publication, the top ten journals have relatively equal quality. See Table 2 .

\subsection{Research direction and literature type}

The research results showed that the number of study direction in nursing of the retrieved documents was 195 , accounts for $29.6 \%$ of all the documents. Other researches covered many disciplines of psychology, social work, oncology, neurology (see Table 3). Considering the literature type, this article main field type was research paper $(73.2 \%)$, followed by meeting $(12.3 \%)$, review $(4.4 \%)$, and others $(10.1 \%)$. It can be seen that

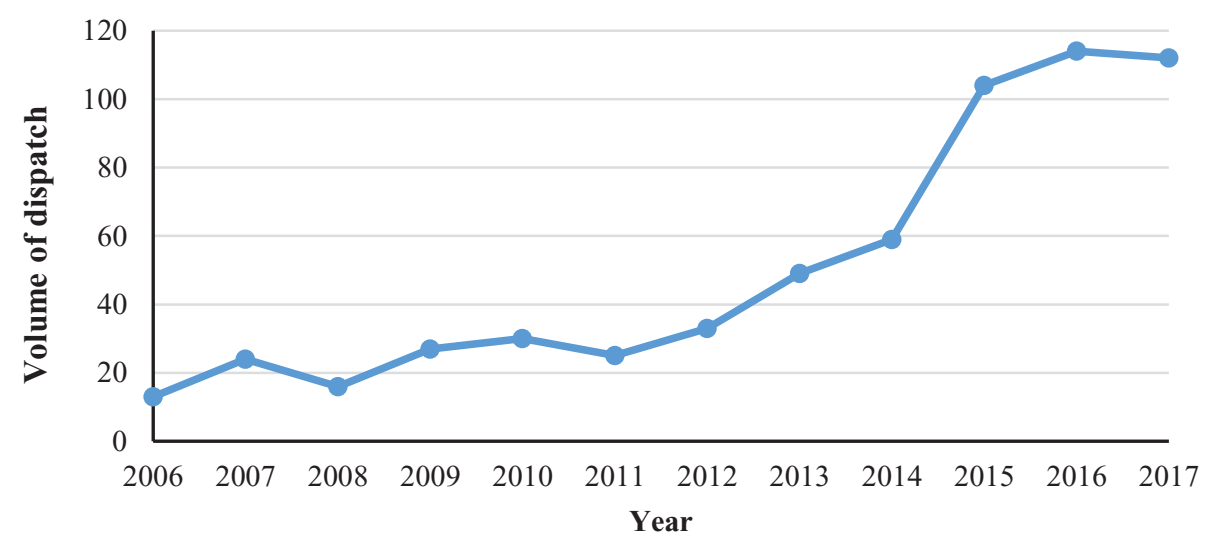

Figure 1. 2006-2017 report of global compassion fatigue. 
the research publication is mainly based on the data type paper.

\subsection{High-frequency key words}

The retrieval results were imported into HistCite, and the WOS database was used to analyze the software. The key words with frequency greater than 55 times and the percentage of total frequency were described (see Table 4). The results showed that the most frequent key

\begin{tabular}{llcc}
\hline Ranking & Country & $\begin{array}{c}\text { Dispatch } \\
\text { volume } \\
\text { (Chapter) }\end{array}$ & Percentage \\
\hline 1 & USA & 335 & 51.4 \\
2 & Australia & 59 & 9.0 \\
3 & Canada & 58 & 8.9 \\
4 & Unknown & 45 & 6.9 \\
5 & UK & 37 & 5.7 \\
6 & Israel & 29 & 4.4 \\
7 & South Africa & 13 & 2.0 \\
8 & South Korea & 12 & 1.8 \\
9 & Italy & 9 & 1.4 \\
10 & New Zealand & 9 & 1.4 \\
11 & Peoples Republic of China & 9 & 1.4 \\
\hline
\end{tabular}

Table 1. Countries in the top 11 cases of compassion fatigue.

\begin{tabular}{|c|c|c|c|c|}
\hline Ranking & Source journal & $\begin{array}{c}2016 \\
\text { IF }\end{array}$ & $\begin{array}{c}\text { Article } \\
\text { quantity } \\
\text { (Chapter) }\end{array}$ & Percentage \\
\hline 1 & $\begin{array}{l}\text { Oncology Nursing } \\
\text { Forum }\end{array}$ & 1.35 & 26 & 4.0 \\
\hline 2 & $\begin{array}{l}\text { Clinical Journal of } \\
\text { Oncology Nursing }\end{array}$ & 0.60 & 20 & 3.1 \\
\hline 3 & $\begin{array}{l}\text { Clinical Social Work } \\
\text { Journal }\end{array}$ & 0.72 & 16 & 2.5 \\
\hline 4 & $\begin{array}{l}\text { Journal of Pain } \\
\text { and Symptom } \\
\text { Management }\end{array}$ & 2.90 & 10 & 1.5 \\
\hline 5 & Gerontologist & 0.94 & 9 & 1.4 \\
\hline 6 & $\begin{array}{l}\text { Journal of Advanced } \\
\text { Nursing }\end{array}$ & 1.99 & 8 & 1.2 \\
\hline 7 & $\begin{array}{l}\text { Arts in } \\
\text { Psychotherapy }\end{array}$ & 0.54 & 6 & 0.9 \\
\hline 8 & $\begin{array}{l}\text { International Journal } \\
\text { of Nursing Studies }\end{array}$ & 3.76 & 6 & 0.9 \\
\hline 9 & $\begin{array}{l}\text { Journal of } \\
\text { Emergency Nursing }\end{array}$ & 0.79 & 6 & 0.9 \\
\hline 10 & $\begin{array}{l}\text { Professional } \\
\text { Psychology: } \\
\text { Research and } \\
\text { Practice }\end{array}$ & 1.39 & 6 & 0.9 \\
\hline
\end{tabular}

Table 2. The top ten journals of compassion fatigue. words were "compassion" and "fatigue". From the highfrequency keywords, we could see that the nurses were more concerned about empathy fatigue and were often associated with key words such as care, stress, and health.

\subsection{Author and issuing agency}

As for the first author and coauthor, the author of this field was "Figley CR", with a total amount of 10 articles (Table 5). Considering the textual agencies, in addition to 26 unsupported sources, the rest of top 10 of the other agencies were universities.

\subsection{High-frequency cited literature}

Application of HistCite special drawing function, according to the time sequence drawing of the literature citation chronological chart, composed of drawing of ellipses and line arrows. The size of the

\begin{tabular}{llcc}
\hline Ranking & Subjects & $\begin{array}{c}\text { Article } \\
\text { quantity } \\
\text { (Chapter) }\end{array}$ & Percentage \\
\hline \hline 1 & Nursing & 195 & 29.6 \\
2 & Psychology & 136 & 20.7 \\
3 & Social work & 91 & 13.8 \\
4 & Oncology & 66 & 10.0 \\
5 & Neurology & 60 & 9.1 \\
6 & General internal medicine & 53 & 8.1 \\
7 & Service of health science & 44 & 6.7 \\
8 & Occupational health in & 33 & 5.0 \\
9 & public environment & 28 & 4.3 \\
10 & Family studies & 23 & 3.5 \\
\hline
\end{tabular}

Table 3. Main directions for the study of compassion fatigue.

\begin{tabular}{llcc}
\hline Ranking & High-frequency key words & Frequency & Percentage \\
\hline \hline 1 & Compassion & 303 & 21.4 \\
2 & Fatigue & 279 & 19.7 \\
3 & Burnout & 108 & 7.6 \\
4 & Nurses & 107 & 7.6 \\
5 & Care & 106 & 7.5 \\
6 & Stress & 79 & 5.6 \\
7 & Secondary & 62 & 4.4 \\
8 & Workers & 61 & 4.3 \\
9 & Health & 59 & 4.2 \\
10 & Trauma & 58 & 4.1 \\
\hline
\end{tabular}

Table 4. High-frequency key words in the study $(n=1413)$ 
elliptical figure represents the number of cited documents; the larger the circle, the higher the citation frequency. The lines with arrows indicate the citation relationship between the documents, and the

\begin{tabular}{clcrr}
\hline Ranking & Authors & $\begin{array}{c}\text { Article quantity } \\
\text { (chapter) }\end{array}$ & TLCS & TGCS \\
\hline \hline 1 & Figley CR & 10 & 325 & 670 \\
2 & Beaumont E & 5 & 3 & 13 \\
3 & Duarte J & 5 & 4 & 9 \\
4 & Pietrantoni L & 5 & 15 & 72 \\
5 & Pinto-Gouveia J & 5 & 4 & 9 \\
6 & Prati G & 4 & 4 & 72 \\
7 & Baum N & 4 & 111 & 260 \\
8 & Bride BE & 4 & 30 & 55 \\
9 & Craigie M & 4 & 2 & 11 \\
10 & Durkin M & & & \\
\hline
\end{tabular}

Note: TLCS: the total cited frequency of the literature in the current analysis of the collection of documents; TGCS: the total cited frequency of the literature in the WOS database.

Table 5. The top 10 authors of the amount of compassion fatigue study. literature cited by the arrow is cited literature. ${ }^{4}$ This study selected GCS (a literature citation in the WOS database) and LCS (a collection of literature is literature citations in the local literature) before 30 , every article for a node, that is drawing on the first 30 nodes, using automatic node numbering system, a chronological chart can display, circle the largest and most of the nodes as the arrow points to the literature number 31 titled "Compassion fatigue: Psychotherapists' chronic lack of self-care", this article in the library of research has the important position of fatigue compassion (see Figure 2).

\section{Discussion}

\subsection{The related research of $\mathrm{CF}$ is increasing, and the regional distribution is uneven}

The statistical analysis showed that since the establishment of the database, the first document of CF originated in the 1990 (relatively young research area), and in 2011, the literature in this field was in a slow growth trend. Since 2011, the literature had increased rapidly,

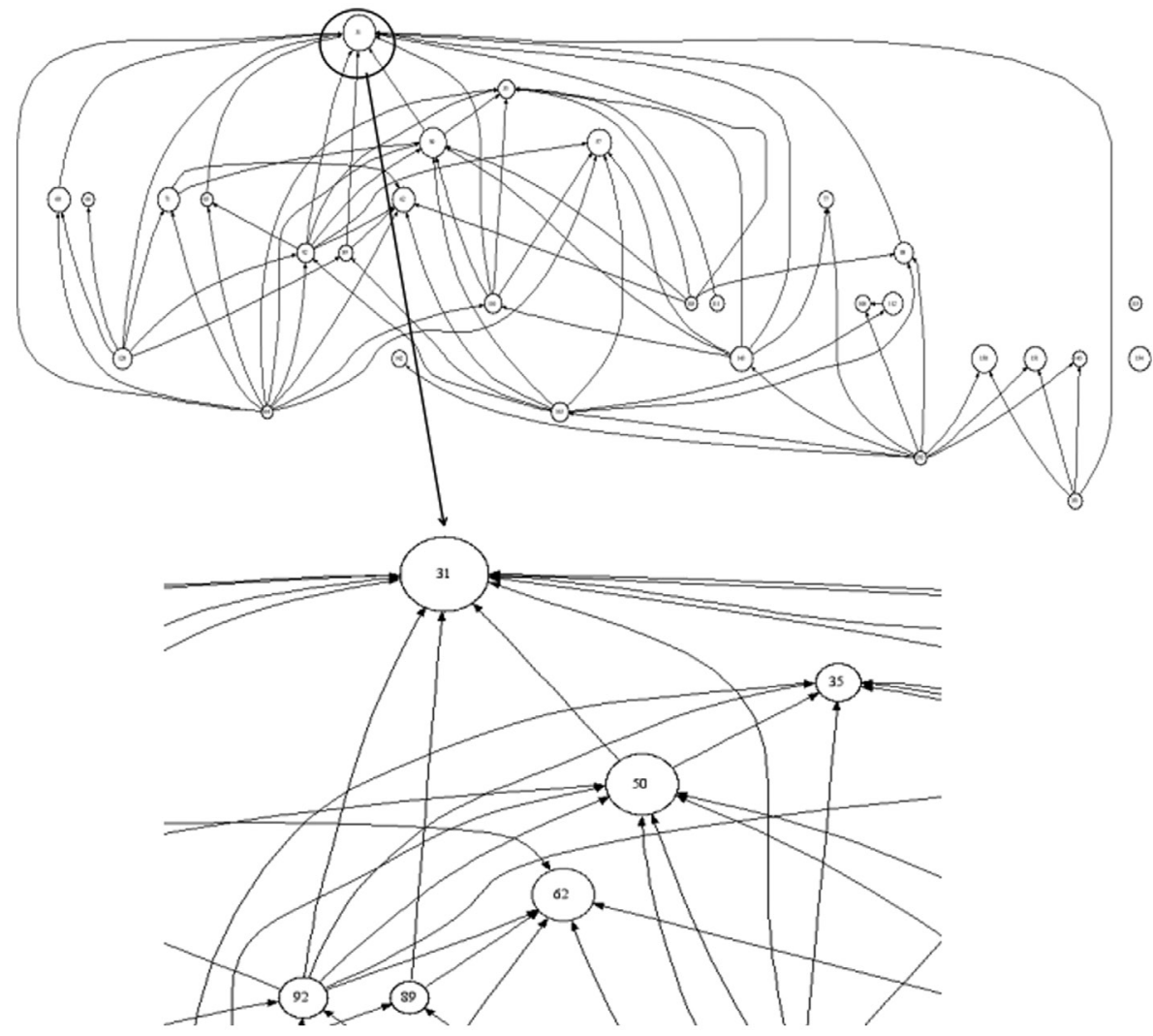

Figure 2. CF citation chronological chart $(n=30)$. 
showing a linear trend. It showed that the research in this field has always been in the state of continuous attention of scholars; especially since 2011, it has become an important topic of concern for international researchers. From the point of view of sending countries and regions, the research in this field showed larger distribution differences. Among them, the United States ranked 335 and was in the first place, followed by Australia and Canada, with less than 100 articles; China's total volume was nine, and it was in the eleventh place, in which analysis found that, ${ }^{5-7}$ the first to write $\mathrm{SCl}$ article was in the source of $2014 .^{8}$ From the content point of view is still in the stage of description of medical staff and patients. The lack of research was on the implementation of the construction section, the relevant management system and effective intervention. It is suggested that domestic scholars should further explore and explore the focus of this field, expand the depth and breadth of research in this field, and improve the international influence.

\subsection{Advocating cooperation among multi-interdisciplinary subjects in this field}

The retrieval and analysis results showed that the main popular subjects of CF were nursing and psychology, followed by social work, oncology, and neurology. All disciplines are independent and interactive. Therefore, it is very necessary to carry out multidisciplinary comprehensive management of target populations, learn from each other's weaknesses, and pay attention to cross-disciplinary cooperation research. ${ }^{9}$ In addition to the field of high-frequency analysis of the key words, it is found that nurses, health, care, health, and so on are closely related to CF. Especially referring to the few literature in China, most of the studies describe the current situation of CF and the cross-sectional survey in special departments (oncology department, psychiatry, hospice care, etc), which is related to burnout and occupational stress ${ }^{10-12}$ in the absence of further deep study, the cooperative research of multidisciplinary and interdisciplinary is still in the blank stage, which can be considered as the direction of future scientific research.

\section{References}

1. Figley CR. Compassion Fatigue as Secondary Traumatic Stress Disorder: An Overview. New York: Brunner-Routledge; 1995:1-20.

\subsection{Pay attention to the core literature and strengthen the research to improve the mental health of the target population}

This research analysis showed that the Journal "Oncology Nursing Forum" has the largest number of publications; most of which were concerning the topic of CF, the higher influence of stationery in the field, and the reference for the whereabouts of new manuscripts. "Figley CR" is not only the writer of the word of empathy fatigue but also the most productive author in the field, who has made a higher contribution to this direction. According to the citation chronological chart, "Compassion fatigue: Psychotherapists' chronic lack of self-care"13 is the highest cited literature, which has a high reference value. This article discusses the concept and model of sympathetic fatigue. It shows that when helping people are good at dealing with traumatic memory and has more effective self-management, they can avoid the occurrence and development of sympathetic fatigue and use case studies to illustrate how to help compassion weary people. From the above research results, we can locate the core documents more efficiently, clarify the development process of this field more conveniently, and find the industry experts who contribute to it, so as to provide some references for scholars in this field.

\section{Conclusions}

The literature of the traceability of CF originated in 1990, and the time was relatively short, but it has always been in the period of continuous attention of scholars. There is still a big gap between China and the developed countries such as the United States and other developed countries in this field, and it is still in the initial stage. The related research is still at the level of description, and the research crowd also mainly pays more attention to the nurse group. The future research should draw more advanced ideas from foreign countries to broaden the depth and breadth of the study so as to improve the mental health of the patients and to help people.

\section{Conflicts of interest}

All contributing authors declare no conflicts of interest.
2. Sheppard K. Compassion fatigue among registered nurses: connecting theory and research. Appl Nurs Res. 2015;28:57-59. 
3. Eugene G. Using hist cite to map the output of small world, Watson-crisk 1953, cell death and differentiation, P. Nicotera and Gene Flow. http://garfield.library.upenn.edu/papers/leicester071103.pdf. Accessed March 12, 2018.

4. Liu L. The analysis of the citations in the library service field based on HistCite. Intell Sci. 2014;32:91-96, 101.

5. Sun B, Hu M, Yu S, Jiang Y, Lou B. Validation of the compassion fatigue short scale among Chinese medical workers and firefighters: a cross-sectional study. BMJ Open. 2016;6:e011279.

6. Yu H, Jiang A, Shen J. Prevalence and predictors of compassion fatigue, burnout and compassion satisfaction among oncology nurses: a cross-sectional survey. Int J Nurs Stud. 2016;57:28-38.

7. Yip SYC, Mak WWS, Chio FHN, Law RW. The mediating role of self-compassion between mindfulness and compassion fatigue among therapists in Hong Kong. Mindfulness. 2017;8:460-470.

8. Onq JC. "Witnessing" or "Mediating" distant suffering? Ethical questions across moments of text, production, and reception. Television New Media. 2014;15:179-196.

9. Zhao H, Duan ZH. Bibliometric analysis of hemophilia nursing research based on Web of Science. PLA J Nurs. 2016;33:1-6 (in Chinese).

10. Li HM, Feng XL, Li YL. Study on compassion fatigue and influencing factors of nurses in hospice care ward. J Nurs Sci. 2017;32:88-90 (in Chinese).

11. Wei H, Huang JT, Shen PH. Study on the relationship between compassion fatigue, occupational stress and job burnout in pre hospital emergency nurses. China Occup Med. 2016;43:155-160 (in Chinese).

12. Liu QM, Wang YY, Tan KY, Wang J, Hu X, Wang $\mathrm{DH}$. Study on the status and influencing factors of compassion fatigue in oncology nurses. Chin Nurs Manag. 2016;16:614-620 (in Chinese).

13. Figley CR. Compassion fatigue: psychotherapists' chronic lack of self care. J Clin Psychol. 2002;58:1433-1441. 